\title{
PELATIHAN PENULISAN KARYA ILMIAH PADA MUSYAWARAH GURU MATA PELAJARAN (MGMP) BAHASA INDONESIA DI SMA/SMK KOTA BENGKULU
}

\section{THE TRAINING OF SCIENTIFIC WRITING AT THE MUSYAWARAH GURU MATA PELAJARAN (MGMP) BAHASA INDONESIA IN SMA/SMK OF BENGKULU CITY}

\author{
Oleh: \\ Nafri Yanti, Fina Hiasa, Arono \\ Jurusan Pendidikan Bahasa dan Sastra Indonesia, FKIP, Universitas Bengkulu \\ Email: nafriyanti@unib.ac.id
}

\begin{abstract}
Initial identification results to the MGMP Indonesian Bengkulu city, it is known that the main problem faced by most teachers is the difficulty to meet Minister of Manpower No. 16 of 2009 and Minister of Education Number 3/V/PB/2010 regarding the obligation of teachers to have publication of scientific papers if want to propose promotion from class 3A. This devotion activity is an effort to overcome the problem. The motives performed in this devotion are lectures, discussions and exercises. Based on hail training, it is known that there is an increase of trainee knowledge on the aspect of understanding on the structure and technique of writing scientific papers by $43 \%$, scientific writing writing tips by $49 \%$, reference information on scientific writing as much as $70 \%$ and information about $77 \%$ publication.
\end{abstract}

Keywords: training, scientific work, $M G M P$

\section{PENDAHULUAN}

Sasaran dalam kegiatan Pengabdian kepada Masyarakat (PPM) ini adalah Musyawarah Guru Mata Pelajaran (MGMP) Bahasa Indonesia SMA/SMK Kota Bengkulu. Salah satu fungsi MGMP adalah sebagai wadah untuk memecahkan permasalaan yang terdapat pada guru yang menjadi anggota di dalamnya. Saat ini jumlah anggota MGPMP Bahasa Indonesia SMA/SMK berjumlah 81 orang, yang terdiri atas 37 orang guru SMK dan 44 orang guru SMA. Berdasarkan hasil identifikasi awal kepada ketua MGMP Bahasa Indonesia Kota Bengkulu Bapak Zon Tusdi, M.Pd., diketahui bahwa saat ini permasalahan utama yang dihadapi oleh sebagian besar guru adalah kesulitan untuk memenuhi Permen Menpan Nomor 16 Tahun 2009 dan Mendiknas Nomor 3/V/PB/2010 tentang aturan perhitungan angka kredit jabatan serta petunjuk pelaksanaan jabatan fungsional guru. Salah satu aturannya berbunyi "Untuk kenaikan jabatan/pangkat setingkat lebih tinggi dari Guru Pertama, pangkat Penata Muda, golongan ruang III/a sampai dengan Guru Utama, pangkat Pembina Utama, golongan ruang IV/e wajib melakukan kegiatan pengembangan keprofesian berkelanjutan pengembangan diri, publikasi dan/atau karya inovatif", (Menpan, 2009).

Dalam kutipan Permen tersebut dijelaskan bahwa guru wajib mempunyai publikasi karya ilmiah jika ingin mengusulkan kenaikan pangkat mulai dari golongan 3A. Peraturan 
ini berlaku terhitung sejak tanggal 1 Januari 2013. Inilah yang menjadi permasalahan utama MGMP Bahasa Indonesia SMA/SMK saat ini. Sebagian besar dari mereka masih kesulitan untuk membuat karya ilmiah. Mereka juga masih minim informasi tentang bagaimana cara agar karya ilmiah yang dihasilkan dapat dipublikasikan. Berdasarkan masalah yang dipaparkan di atas, dibutuhkan suatu pelatihan khusus yang dapat memfasilitasi guru-guru MGMP Bahasa Indonesia SMA/SMK Kota Bengkulu untuk meningkatkan keterampilan menulis karya ilmiah dan juga dapat mempublikasikannya. Untuk itu diharapkan pelatihan ini dapat dilaksanakan sesegera mungkin demi meningkatnya keterampilan guru-guru di MGMP Bahasa Indonesia SMA/SMK Kota Bengkulu agar dapat menghasilkan karya ilmiah yang terpublikasi.

Tuntutan tersebut tidak berbanding lurus dengan kenyataan dilapangan. Berdasarkan hasil observasi awal diketahui bahwa menulis karya ilmiah masih merupakan hal yang sulit dilaksanakan khususnya bagi dewan guru yang tergabung dalam MGMP Bahasa indonesia SMA/SMK Kota Bengkulu. Melakukan berbagai kegiatan pelatihan, workshop dan berbagai kegitan pertemuan ilmiah telah terbukti efektif untuk meningkatkan kemampuan menulis karya ilmiah guru. Misalnya penelitian yang dilakukan oleh (Udiyono, 2011) dengan hasil secara bersama-sama terdapat hubungan positif yang signifikan antara kompetensi professional, keikut sertaan dalam forum ilmiah dan karya pengembangan profesi dengan kinerja guru $(\mathrm{Ry}, 123)=0,888$ dengan koefisien determinasi (R2) sebesar 0,788 harga $\mathrm{F}$ regresi $=50,881$ signifikan pada taraf signifikasi $5 \%$. Berbagai kegiatan workshop dan pelatihan juga tentang menulis karya ilmiah untuk dewan guru juga pernah dilakukan oleh (Supriatna \& Muslim, 2015) dengan judul kegiatan Workshop Karya Tulis Ilmiah Bagi Guru SD Negeri Jipang, (Wening \& Dkk, 2009) dengan judul kegiatan Workshop Penulisan Karya Ilmiah Sebagai Upaya Pengembangan Profesionalisme Guru SMK. Berdasarkan hasil kegiatan tersebut diketahui bahwa terjadi peningkatan kemampuan menulis karya ilmiah dewan guru yang menjadi sasaran kegiatan setelah dilakukannya workshop terkait penulisan karya ilmiah. Oleh karena itu kegiatan sejenis perlu untuk segera dilkukan agar kemampuan menulis karya ilmiah dewan guru yang tergabung dalam MGMP Bahasa Indonesia SMA/SMK Kota Bengkulu juga dapat meningkat.

Dalam kegiatan ini tim pengabdi akan menggunakan berbagai referensi yang terkait dengan karya ilmiah diantaranya buku Menulis Karya Ilmiah (Dalman, 2013), buku yang berjudul Lincah Menulis Artikel Ilmiah (Purwarna, 2017) dan referensi dari (Nurgiyantoro, 2001) tentang penilaian pengajaran bahasa yang diharapkan dapart menjadi sumber inspirasi bagi guru untuk dapat produktif dalam menulis karya ilmiah.

\section{METODE PENGABDIAN}

Dalam melaksanakan gegiatan beberapa metode yang digunakan adalah sebagai berikut:

1. Ceramah dan Tanya Jawab. Metode ini dipilih untuk menjelaskan tentang materi yang bersifat teoritik terkaitdengan aturan perundangan yang menyangkaut kenaikan pangkat menurut Peraturan Menteri Pendayagunaan Aparatur Negara dan Reformasi Birokrasi No.16 Tahun 2009. Selain itu juga bermacam-macam karyatulis ilmiah, utamanya makalah, laporan penelitian tindakan kelas dan diktat serta bagaimana cara untuk mempublikasikannya.

2. Demonstrasi. Metode ini digunakan untuk menjelaskan suatu proses kerja secara bertahapsehingga dapat memberi kemudahan bagi peserta dapat mengamati secara 
cermatproses pembuatan karya tulis ilmiahdari persiapan sampai jadi diktat, laporanpenelitian dan makalah.

3. Latihan/Praktek atau tutorial. Pada metode ini peserta mempraktekkan pembuatan karya tulis ilmiah denganbimbingan pelatih sehingga peserta dapat membuat karya tulis ilmiah dengan baik.

\section{HASIL DAN PEMBAHASAN}

Kegiatan pelatihan penulisan karya ilmiah Musyawarah Guru Mata Pelajaran Bahasa Indonesia SMA/SMK Kota Bengkulu dilaksanakan pada hari Senin tanggal 19 Juni 2017. Peserta pelatihan yang hadir berjumlah 35 orang. Kegiatan pelatihan dilaksanakan dari pukul 08.00 WIB sampai dengan pukul 17.00 WIB. Sebelum memulai kegiatan inti pelatihan, pengabdi mengadakan survei kepada peserta tentang beberapa hambatan pada aspek kognitif yang menyebabkan masih rendahnya kemampuan menulis dan publikasi karya ilmiah peserta pelatihan.

Dari hasil survei diketahui bahwa hal tersebut terjadi dikarenakan masih minimnya pengetahuan guru tentang teknik penulisan karya ilmiah, kurangnya pemahaman tentang struktur karya ilmiah, serta terbatasnya informasi tentang referensi yang dapat digunakan untuk menulis karya ilmiah dan informasi jurnal-jurnal yang tersedia sebagai media publikasi karya ilmiah yang telah dihasilkan. Secara lebih rinci faktor-faktor penghambat tersebut tergambar dalam diagram berikut:

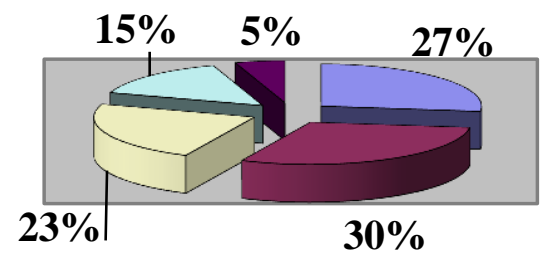

\section{口Pemaham struktur}

口Teknik penulisan

Gambar 1. Faktor utama rendahnya publikasi karya ilmiah guru MGMP bahasa Indonesia SMA/SMK Kota Bengkulu pada aspek faktor kemampuan.

Diagram tersebut menunjukan bahwa faktor utama masih rendahnya publikasi karya ilmiah guru yang tergabung dalam MGMP Bahasa Indonesia SMA/SMK Kota Bengkulu adalah pemahaman tentang teknik penulisan yaitu sebesar $30 \%$ atau sebanyak 11 orang dari peserta pelatihan. Faktor lain yang menyebabkan rendahnya tingkat publikasi karya ilmiah peserta pelatihan yaitu kurangnya pemahaman struktur, referensi dan media publikasi karya ilmiah yang telah mereka hasilkan.

Selain faktor kemampuan, faktor lain yang menyebabkan rendahnya tingkat publikasi karya ilmiah peserta pelatihan adalah faktor psikologis dan faktor ekonomi. Faktor psikologis.

Tim pengabdi juga memberikan informasi tentang alamat web yang mempublikasikan banyak tulisan ilmiah dari berbagai daerah. Tulisan tersebut tentunya dapat dijadikan sebagai referensi baik dari segi strutur penulisan karya ilmiah dalam bentuk artikel, maupun referensi tentang penelitian-penelitian yang relevan dengan 


\section{Dharma Raflesia Unib Tahun XVI, Nomor 1 Juni 2018}

penelitian yang akan dilakukan oleh guru tersebut. Alamat web yang dapat diakses sebagai referensi penulisan karya ilmiah diantaranya:

1. http://ejournal.upi.edu/index.php/IJAL/index

2. Pustaka ilmiah.com

3. http://id.portalgaruda.org/?ref=home

4. http://journal.asiatefl.org/

5. http://www.journal.tarbiyahiainib.ac.id/index.php/attalim

6. https://owl.english.purdue.edu/owl/resource/560/01/

7. http://www.conferencealerts.com/

8. Jurnal Ling Tera.com

Dan beberapa laman web yang terkait dengan penulisan karya ilmiah mulai dari referensi penulisan karya ilmiah hingga cara pengecekan plagiasi sebuah karya ilmiah.

\begin{tabular}{|c|c|c|}
\hline 1 & www.scimagojr.com & $\begin{array}{l}\text { Salah satu laman jurnal internasional } \\
\text { bereputasi }\end{array}$ \\
\hline 2 & $\begin{array}{l}\text { http://scholarlyoa.com/publi } \\
\text { shers/ }\end{array}$ & melihat questionable journal dan publisher \\
\hline 3 & $\begin{array}{l}\text { www.microsoftacademicsear } \\
\text { ch.com }\end{array}$ & Salah satu laman jurnal internasional \\
\hline 4 & http://issn.lipi.go.id/ & cek issn \\
\hline 5 & www.doaj.com & melihat jurnal INA masuk list \\
\hline 6 & $\begin{array}{l}\text { www.plagiarisma.net, } \\
\text { http://www.scanmyessay.co } \\
\underline{\mathrm{m} /},\end{array}$ & $\begin{array}{l}\text { cek plagiat karya ilmiah di laman open access, } \\
\text { Plagiarisma dan viper }\end{array}$ \\
\hline 7 & $\begin{array}{l}\text { http://www.duplichecker.co } \\
\underline{\mathrm{m} /}\end{array}$ & $\begin{array}{l}\text { cek plagiat karya ilmiah dl laman open access } \\
\text { duplichecker }\end{array}$ \\
\hline 8 & www.ithenticate.com & idem no. 7 tapi termasuk laman subscribe \\
\hline
\end{tabular}

\begin{tabular}{|c|c|c|}
\hline 9 & 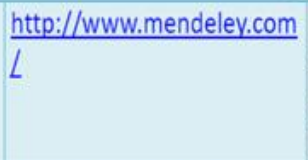 & $\begin{array}{l}\text { one of Reference management } \\
\text { software. . Supported Site bisa } \\
\text { dijadikan referensi utk mencari jurnal } \\
\text { internasional bereputasi }\end{array}$ \\
\hline 10 & www.pubmed.com & laman jurnal ilmiah bidang Kesehatan \\
\hline 11 & $\begin{array}{l}\text { http://www.elsevier.com/i } \\
\text { ournal- } \\
\text { authors/home\#find-a- } \\
\text { journal }\end{array}$ & melihat cara penulisan artikel \\
\hline 12 & $\begin{array}{l}\text { http://www.elsevier.com/e } \\
\text { Isevier-products/procedia }\end{array}$ & $\begin{array}{l}\text { melihat e-proceeding yang disediakan } \\
\text { scopus }\end{array}$ \\
\hline 13 & $\begin{array}{l}\text { http://www.scopus.com/s } \\
\text { earch/form/authorFreeLoo } \\
\text { kup.url }\end{array}$ & $\begin{array}{l}\text { untuk melihat tulisan seseorang } \\
\text { apakah sudah terindeks di scopus } \\
\text { atau tidak }\end{array}$ \\
\hline 14 & http://easychair.org/ & Conference management system \\
\hline
\end{tabular}




\begin{tabular}{|l|l|l|}
\hline 15 & http://teji.com/ip/url-to-ip- & Laman untuk melihat lokasi \\
address.aspx & $\begin{array}{l}\text { suatu URL dengan merobah ke } \\
\text { IP adress }\end{array}$ \\
\hline 16 & http://repec.org/ & $\begin{array}{l}\text { Laman utk melihat PT dan } \\
\text { penulis paling produktif } \\
\text { dibidang ekonomi }\end{array}$ \\
\hline 17 & http://www.harzing.com/pop.htm & $\begin{array}{l}\text { Laman utk melihat publikasi } \\
\text { dan paper. Harus di unduh } \\
\text { dahulu dan .exe di run }\end{array}$ \\
\hline 18 & OJS (Open Journal System) & $\begin{array}{l}\text { Utk membuat jurnal on line, } \\
\text { free }\end{array}$ \\
\hline 19 & http://garuda.dikti.go.id/ & Portal garuda dikti \\
\hline 20 & http://id.portalgaruda.org & $\begin{array}{l}\text { IPI ( Indonesia Publication } \\
\text { Index)-IAES }\end{array}$ \\
\hline 21 & http://www.isbn-check.com/ & Cek ISBN \\
\hline
\end{tabular}

Pada saat tim pengabdi memberikan penjelasan, peserta pelatihan menyimak dengan serius penjelasan yag diberikan.

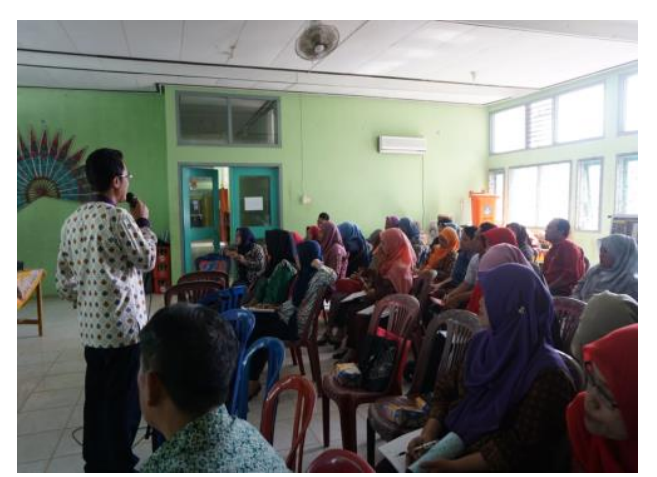

Gambar 2. Peserta pelatihan menyimak dengan serius materi yang disajikan oleh tim pengabdi

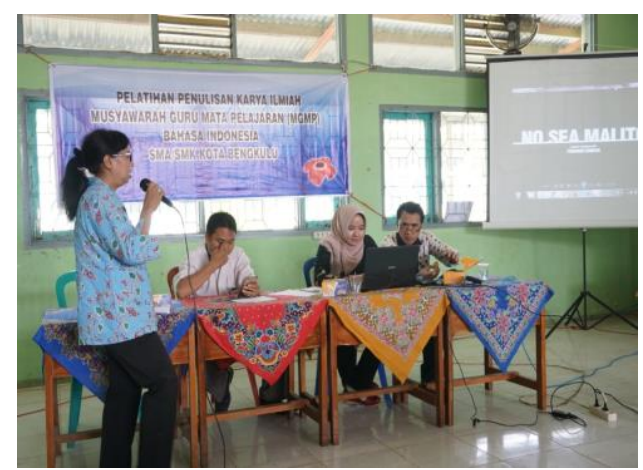

Gambar 3. Salah satu peserta pelatihan antusias menyampaikan pengalamannya terkait penulisan karya ilmiah

Tim pengabdi juga menjelaskan bahwa di Universitas Bengkulu juga telah mempunyai beberapa jurnal sebagai wadah untuk mempublikasikan karya ilmiah guruguru khususnya guru bahasa Indonesia di Provinsi Bengkulu. Jurnal tersebut diantaranya 
jurnal Wacana dan jurnal Bisa. Kedua jurnal tersebut merupakan jurnal yang dimiliki jurusan Pendidikan Bahasa dan Seni sehingga sangat relevan bagi guru untuk mempublikasikan karya ilmiah mereka yang temanya berkaitan erat dengan pembahasan seputar pendidikan, bahasa dan sastra indonesia.

Dalam melaksanakan kegiatan pengabdian, tim pengabdi juga menemukan beberapa faktor yang mendukung dan menghambat kegiatan, yaitu:

a. Faktor Pendukung

1. Pengurus MGMP Bahasa Indonesia SMA/SMK Kota Bengkulu merespon dengan baik tim pengabdi untuk melaksanakan kegiatan pengabdian berupa pelatihan penulisan karya ilmiah.

2. Dewan guru yang tergabung dalam MGMP Bahasa Indonesia SMA/SMK Kota Bengkulu mempunyai motivasi yang cukup tinggi untuk belajar hal ini ditunjukan dengan antusiasme mereka dalam mengikuti proses pelatihan.

3. Fasilitas yang disediakan oleh tim pengurus MGMP Bahasa Indonesia SMA/SMK Kota Bengkulu berupa tempat, media untuk memberikan pelatihan cukup respentatif mendukung kegiatan pengabdian.

4. MGMP Bahasa Indonesia SMA/SMK Kota Bengkulu merupakan wadah yang aktif mengadakan pertemuan untuk membahas kesulitan-kesulitan yang dihadapi anggotanya.

\section{b. Faktor Penghambat}

1. Kesibukan guru dan singkatnya tenggang waktu pemberian undangan dengan pelaksanaan kegiatan menyebabkan guru belum menyiapkan contoh karya ilmiah yang telah merekan buat.

2. Keterbatasan fasilitas pendukung (waktu dan dana) menyebabkan pelatihan yang diberikan belum terlalu mendalam.

3. Saat ini kuota yang disiapkan oleh pemerintah untuk memberikan pelatihan-pelatihan terkait penulisan karya ilmiah masih terbatas, sehingga pengetahuan guru tentang karya ilmiah masih sangat minim. Oleh karena itu guru membutuhkan pelatihan yang lebih intensif lagi.

Setelah kegiatan pelatihan selesai dilaksakan tim pengabdi juga melakukan evaluasi. Salah satu cara yang dilakukan untuk mengevaluasi peserta adalah dengan memberikan instrumen yang berisi beberapa pertanyaan untuk mengukur sejauh mana peningkatan pengetahuan peserta terhadap beberapa hal berikut:

1) Struktur dan teknik penulisan karya ilmiah.

2) Informasi guru terhadap alamat web yang tersedia agar dapat mengakses jurnal online yang dapat dijadikan referensi penulisan karya ilmiah.

3) Iinformasi guru terhadap jurnal-jurnal yang tersedia khusunya di UNIB sebagai media publikasi karya ilmiah yang telah dihasilkan.

Setelah kegiatan pelatihan selesai dilaksakan tim pengabdi juga melakukan evaluasi. Salah satu cara yang dilakukan untuk mengevaluasi peserta adalah dengan memberikan instrumen yang berisi beberapa pertanyaan untuk mengukur sejauh mana peningkatan pengetahuan peserta terhadap beberapa hal berikut:

1) Struktur dan teknik penulisan karya ilmiah.

2) Informasi guru terhadap alamat web yang tersedia agar dapat mengakses jurnal online yang dapat dijadikan referensi penulisan karya ilmiah.

3) Iinformasi guru terhadap jurnal-jurnal yang tersedia khusunya di UNIB sebagai media publikasi karya ilmiah yang telah dihasilkan. 
Dari hasil evaluasi diketahui bahwa ada capaian peningkatan pengetahuan peserta, mulai dari teknik penulisan hingga publikasi karya ilmiah sebelum dan setelah dilaksanakannya pelatihan. Peningkatan tersebut tergambar pada tabel berikut:

Tabel 1. Hasil evaluasi pelatihan penulisan karya ilmiah musyawarah guru mata pelajaran bahasa Indonesia SMA/SMK Kota Bengkulu

\begin{tabular}{|c|c|c|c|c|c|c|c|c|}
\hline \multirow[b]{2}{*}{ No } & \multirow[b]{2}{*}{ Indikator Penilaian } & \multicolumn{3}{|c|}{ Sebelum Pelatihan } & \multicolumn{3}{|c|}{ Setelah Pelatihan } & \multirow[b]{2}{*}{$\begin{array}{c}\text { Ratio } \\
\text { peningkatan }\end{array}$} \\
\hline & & Paham & $\begin{array}{l}\text { Tidak } \\
\text { paham }\end{array}$ & $\begin{array}{c}\text { Persentase } \\
\text { tingkat } \\
\text { pemahaman }\end{array}$ & Paham & $\begin{array}{l}\text { Tidak } \\
\text { paham }\end{array}$ & $\begin{array}{c}\text { Persentase } \\
\text { tingkat } \\
\text { pemahaman }\end{array}$ & \\
\hline 1 & $\begin{array}{c}\text { Struktur dan teknik } \\
\text { penulisan }\end{array}$ & 15 & 20 & $43 \%$ & 30 & 5 & $86 \%$ & $43 \%$ \\
\hline 2 & Tips penulisan & 10 & 25 & $29 \%$ & 27 & 8 & $77 \%$ & $49 \%$ \\
\hline 3 & Informasi referensi & 3 & 32 & $9 \%$ & 28 & 7 & $80 \%$ & $71 \%$ \\
\hline 4 & Media publikasi & 3 & 32 & $9 \%$ & 30 & 5 & $86 \%$ & $77 \%$ \\
\hline
\end{tabular}

Berdasarkan data pada tabel tersebut diketahui bahwa ada peningkatan pengetahuan peserta pelatihan pada aspek pemahaman terhadap struktur dan teknik penulisan karya ilmiah, data menunjukkan bahwa sebelum pelatihan terdapat 15 peserta yang memahami tentang struktur dan teknik penulisan karya ilmiah sedangkan 20 peserta lainnya belum memahami hal tersebut. Setelah dilakukan pelatihan diketahui bahwa jumlah peserta yang memiliki pemahaman dan teknik penulisan karya ilmiah meningkat menjadi 30 0rang atau terjadi peningkatan sebesar $43 \%$.

Selain itu juga terjadi peningkatan pengetahuan tentang tips penulisan karya ilmiah yang sebelum dilakukan pelatihan diketahui hanya 10 0rang yang memahami tips penulisan karya ilmiah dan setelah dilakukan pelatihan jumlah tersebut meningkat menjadi 27 orang atau terjadi peningkatan sebesar $49 \%$.

Berdasarkan data pada tabel diketahui juga bahwa terdapat peningkatan pengetahuan peserta tentang informasi referensi penulisan karya ilmiah. Sebelum dilakukan pelatihan diketahui bahwa peserta yang mengetahui informasi tentang referensi yang dapat diakses melaui internet hanya terdiri 3 orang, namun setelah dilakukan pelatihan jumlah tersebut meningkat menjadi 28 orang, atau terjadi peningkatan sebersar $70 \%$.

Data survei juga menunjukan bahwa terjadi peningkatan informasi peserta pelatihan pada aspek media publikasi. Sebelum dilakukan pelatihan diketahu hanya 3 orang yang mengaetahu media publikasi karya ilmiah yang telah dihasilkan namaun setelah dilakukan pelatihan diketahui bahwa 30 peserta mengetahui informasi tentang media publikasi karya ilmiah, peningkatan terjadi sebesar $77 \%$.

\section{KESIMPULAN DAN SARAN}

\section{Kesimpulan}

Berdasarkan hasil kegiatan pengabdian diketahui bahwa terdapat 3 (tiga) faktor penyebab masih rendahnya publikasi karya ilmiah yang dilakukan oleh guru yang tergabung pada kelompok MGMP Bahasa Indonesia SMA/SMK Kota Bengkulu. Beberapa faktor tersebut adalah faktor kemampuan, psikologis, ekonomi. Dari ketiga faktor tersebut faktor utama penyebab masih rendahnya publikasi karya ilmiah yang dilakukan oleh guru 
yang tergabung pada kelompok MGMP Bahasa Indonesia SMA/SMK Kota Bengkulu adalah faktor kemampuan. Faktor kemampuan tersebut dikarenakan masih terbatasnya informasi tentang: 1) Struktur dan teknik penulisan karya ilmiah, 2) Tips penulisan karya ilmiah, 3) Informasi tentang referensi yang dapat diakses secara online tentang struktur penulisan karya ilmiah dan contoh-contoh penelitian yang dapat dilakukan, dan 4) Informasi jurnal-jurnal yang tersedia sebagai media publikasi karya ilmiah yang telah dihasilkan.

Pelatihan yang dilakukan sudah cukup efektif. Hal ini dapat dilihat dari hasil evaluasi yang menunjukan ada peningkatan pengetahuan peserta pelatihan pada aspek pemahaman terhadap struktur dan teknik penulisan, tips penulisan, sumber referensi dan media publikasi karya ilmiah.

\section{Saran}

Diharapakan untuk kedepannya pelatihan-pelatihan sejenis dapat terus dilakukan. Diharapkan juga pelatihan yang diberikan dapat lebih banyak menjangkau jumlah peserta dengan fasilitas yang lebih baik lagi. Pelatihan yang diberikan kedepannya diharap juga dapat dilakukan dengan waktu yang lebih lama agar materi yang dibahas dapat di bahasa secara lebih mendalam, sehingga dapat meningkatkan kualitas guru, khususnya guru yang tergabung pada kelompok MGMP Bahasa Indonesia SMA/SMK Kota Bengkulu.

\section{DAFTAR PUSTAKA}

Dalman, 2013, Menulis Karya Ilmiah, Rajawali Pers: Jakarta.

Depdiknas Dirjen Dikdasmen Direktorat Tnaga Kependidikan, 2010, Pedoman Penyusunan Karya Tulis Ilmiah di Bidang Pendidikan dan Angka Kredit Pengembangan Profesi Guru: Jakarta.

Nurgiyantoro, B, 2001, Penilaian Dalam Pengajaran Bahasa, BPFE: Yogyakarta.

Peraturan Menteri Pendayagunaan Aparatur Negara dan Reformasi Birokrasi No. 16 Tahun 2009 tentang Jabatan Fungsional Guru dan Angka Kreditnya

Purwarna, D, 2017, Lincah Menulis Artikel Ilmiah Populer \& Jurnal, Grafindo Persada: Jakarta.

Supriatna, \& Muslim, A, 2015, Workshop Karya Tulis Ilmiah Bagi Guru Sd Negeri Jipang. In Proceeding Seminar LPPM UMP (hal. 102-105), UMP: Purwekerto. Diambil dari http://download.portalgaruda.org/article.php?article=362968\&val=7672\&title =IBM KELOMPOK KERJA GURU SD NEGERI JIPANG (WORKSHOP KARYA TULIS ILMIAH BAGI GURU SD NEGERI JIPANG)

Udiyono, 2011, Pengaruh Komptensi Profesional dan Keikutsertaan Guru Dalam Forum Ilmiah Serta Karya Pengembangan Profesi Terhadap Kinerja Guru. Magistra, 23(76):1-9. Diambil dari http://id.portalgaruda.org/?ref=search\&mod=document\& select=title \&q=+karya+ilmiah+guru\&button=Search+Document

Wening, S, dkk., 2009, Workshop Penulisan Karya Ilmiah Sebagai Upaya Pengembangan Profesionalisme Guru SMK, INOTEK, 13:171-181. Diambil dari http://id.portalgaruda.org/?ref=browse\&mod=viewarticle \&article= 355629 